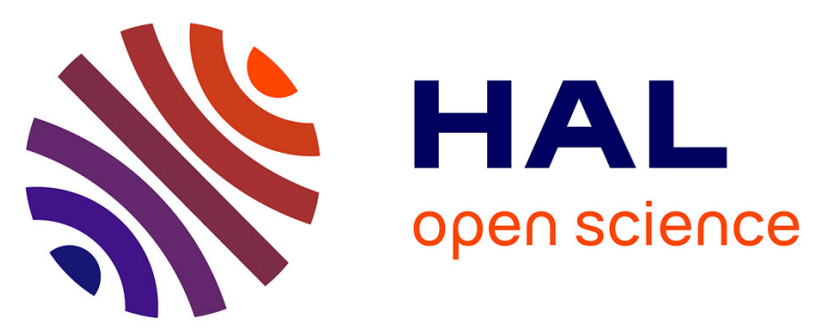

\title{
Study of the microstructure and mechanical properties obtained by Laser Boost in SLM process for the Ti-64 alloy
}

Caroline Widomski, Denis Solas, Francois Brisset, Anne-Laure Helbert, Thierry Baudin, Sebastien Lebel

\section{To cite this version:}

Caroline Widomski, Denis Solas, Francois Brisset, Anne-Laure Helbert, Thierry Baudin, et al.. Study of the microstructure and mechanical properties obtained by Laser Boost in SLM process for the Ti-64 alloy. Materials Science Forum, 2021. hal-03035530v2

\section{HAL Id: hal-03035530 \\ https://hal.science/hal-03035530v2}

Submitted on 20 Jul 2021

HAL is a multi-disciplinary open access archive for the deposit and dissemination of scientific research documents, whether they are published or not. The documents may come from teaching and research institutions in France or abroad, or from public or private research centers.
L'archive ouverte pluridisciplinaire HAL, est destinée au dépôt et à la diffusion de documents scientifiques de niveau recherche, publiés ou non, émanant des établissements d'enseignement et de recherche français ou étrangers, des laboratoires publics ou privés. 


\title{
Study of the microstructure and mechanical properties obtained by Laser Boost in SLM process for the Ti-64 alloy
}

\author{
Caroline Widomski ${ }^{1, a^{*}}$, Denis Solas ${ }^{1, b}$, François Brisset ${ }^{1, c}$, Anne-Laure \\ Helbert $^{1, d}$, Thierry Baudin ${ }^{1, e}$, Sebastien Lebel ${ }^{2, f}$ \\ ${ }^{1} \mathrm{ICMMO}, \mathrm{SP} 2 \mathrm{M}$, University Paris-Saclay, UMR CNRS 8182, Orsay, France \\ ${ }^{2}$ AddUp, 5 Rue Bleue, Cébazat, France
}

\begin{abstract}
caroline.widomski@universite-paris-saclay.fr a , denis.solas@universite-paris-saclay.fr b, francois.brisset@universite-paris-saclay.fr ${ }^{\mathrm{c}}$, anne-laure.helbert@universite-paris-saclay.fr ${ }^{\mathrm{d}}$, thierry.baudin@universite-paris-saclay.fr ${ }^{\mathrm{e}}$, sebastien.lebel@addupsolutions.com ${ }^{\dagger}$
\end{abstract}

Keywords: Additive Manufacturing, SLM, Titanium, Ti-64, Microstructure, Mechanical properties, HIP

\begin{abstract}
Selective laser melting (SLM) is one of the new additive manufacturing techniques in which complex parts can be created directly by selectively melting layers of powder. If the productivity of the process is too fast, defects (porosity, partially melted powder, spatters ...) are generated inside the fabricated parts and can deteriorate the mechanical properties of the product. A new Laser Boost strategy with a larger melting area and a productivity of $43.20 \mathrm{~cm}^{3} / \mathrm{h}$ has been compared to a Linear Classic strategy. Ti-64 alloy samples were elaborated with both strategies to study their influence on microstructure and mechanical properties. Laser Boost strategy leads to the formation of Ti-64 prior $\beta$ grains that are larger than the Linear Classic strategy. Mechanical properties obtains are similar with both strategies with a maximum strength average around $1250 \mathrm{MPa}$ and an elongation at failure between 3 and 9\%. A thermal post-processing by Hot Isostatic Pressure have been carried out on samples made by Laser Boost to increase the ductility of the material up to $15 \%$.
\end{abstract}

\section{Introduction}

The Selective Laser Melting (SLM) powder bed process is one of the most attractive technique for building parts with a high degree of complexity as indicated in the work by Kruth et al. [1]. The fabrication of a product is formed by selectively melting successive layers of metallic powder by the interaction of a laser beam. However, as the basis of this technology is a particle welding process, defects (such as porosity, lack of fusion or laser spatters) are generated inside the fabricated parts [2] and can deteriorate the mechanical properties of the product. Moreover, many studies have been carried out on the SLM method with a linear laser path which induces a low productivity to have good properties. To solve these problems of defect, some related studies have revealed that the process parameters, such as laser power, scan speed, layer thickness and area irradiated by the laser can influence the properties. To increase the productivity of the process, two ways are possible: increasing the laser speed or increasing the melting area. This paper study the influence of a new laser strategy: the Laser Boost (LB). This strategy allows a wider melting area and melt a larger quantity of powder which will induce a better productivity than the Classic Linear (CL) strategy. The aim of this work is to compare the influence of these two strategies on the microstructure and the mechanical properties of a Ti-64 alloy. Moreover, the impact of Hot Isostatic Pressure (HIP) post-treatment, is also investigated. Scanning Electron Microscope (SEM) and Electron BackScatter Diffraction (EBSD) were used to characterize the microstructure. The $\beta$ grain reconstruction from a phase is used to show the influence of the strategy on the prior beta grain microstructure. Tensile test samples were elaborated and machined to measure the mechanical tensile properties. 


\section{Experimental conditions}

\subsection{Material and process}

The powder of Ti-64 alloy (titanium base, $6 \%$ aluminium and $4 \%$ of vanadium) was manufactured by gas atomization method and the spherical particle size ranged from $5 \mu \mathrm{m}$ to $25 \mu \mathrm{m}$. In this study, all samples were built by AddUp company using a FormUp 350 SLM machine. Because of the high chemical reactivity of titanium alloys with oxygen, the build chamber was filled with argon. This process generates a high temperature gradient with a cooling rate of $10^{5}-10^{7} \mathrm{~K} / \mathrm{s}$ [3] [4] that leads to grain growth of $\beta$ phase by epitaxy between the fused layers and induce a columnar structure with a solidification direction parallel to the building direction [5]. The resulting microstructure of Ti-64 fabricated by SLM process is very fine acicular martensitic $\alpha^{\prime}$ resulting from columnar grains $\beta$ [6]. In this study, the CL and the LB strategies were compared. The LB strategy use a larger melting area with a higher power and a lower scan speed in comparison to the CL strategy. Tensile specimens (Fig. 1) were built vertically in the build-up direction. The laser scanning path use a unidirectional scanning with a $90^{\circ}$ rotation between each layer (Fig. 1).

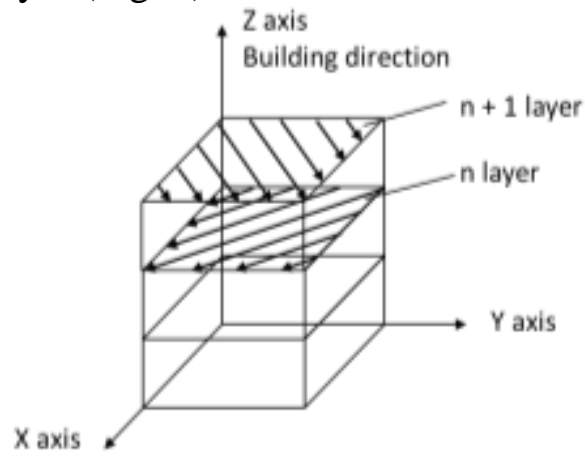

Fig. 1: Laser scanning path

The Volume Energy Density $\left(\mathrm{J} / \mathrm{mm}^{3}\right)$ was calculated for both strategies as follows (Eq.1):

$$
\mathrm{VED}=\frac{\mathrm{P}}{\mathrm{V}_{\mathrm{s}} \times \mathrm{H} \times \mathrm{L}}
$$

With $\mathrm{P}=$ laser power $(\mathrm{W}), \mathrm{V}_{\mathrm{s}}=$ scan speed $(\mathrm{mm} / \mathrm{s}), \mathrm{H}=$ layer thickness $(\mathrm{mm}), \mathrm{L}=$ spacing between laser hatching vectors $(\mathrm{mm})$. The CL is performed with a VED of $20.8 \mathrm{~J} / \mathrm{mm}^{3}$ and the LB with a VED of $38.5 \mathrm{~J} / \mathrm{mm}^{3}$ with two different powers such as $\mathrm{P}_{2}$ is higher than $\mathrm{P}_{1}$. The productivity of the CL strategy is $12.96 \mathrm{~cm}^{3} / \mathrm{h}$ and the productivity of the LB is $43.20 \mathrm{~cm}^{3} / \mathrm{h}$.

\subsection{Post-treatments}

After fabrication, two different thermal treatments were performed. The first "lot" underwent a stressrelieve treatment at $300^{\circ} \mathrm{C}$ during $2 \mathrm{~h}$ with a natural cooling in the furnace. The second "lot" underwent Hot Isostatic Pressing (HIP) treatment at $920^{\circ} \mathrm{C}$ during $2 \mathrm{~h}$ under 1000 bar using argon gaz. This HIP treatment is frequently used as a post-treatment to reduce the internal porosity and improve the mechanical properties [7]. After the densification process, a natural slow cooling in the HIP system was performed with a cooling speed of $2.710^{2} \mathrm{~K} / \mathrm{s}$ versus $10^{5}-10^{7} \mathrm{~K} / \mathrm{s}$ for a raw manufacturing sample. According to the TRC diagram [8], the equilibrium phases obtained are $\alpha$ and $\beta$ phases.

\subsection{Microstructure characterization and mechanical tests}

Examination of the microstructure occurred after grinding with $\mathrm{SiC}$ paper up to a fine 2400 grid size and then an electro-chemical polishing is carried out with the Struers A3 electro-class used for polishing titanium alloys. Microstructure and crystallographic orientation were examined by EBSD. Tensile tests were performed according to the ASTM E8/E8M standard. The ultimate tensile strength $(\mathrm{Rm})$ and fracture elongation (A\%) were obtained as direct output from the tensile test. Zeiss Sigma HD Scanning Electron Microscope (SEM) was used to analyze the fracture surface of the tensile specimens. 


\section{Results}

\subsection{Microstructure}

The Fig.2 (a) and (b) show EBSD microstructures of the (XY) plane obtained with both strategies. The microstructure is composed of martensitic $\alpha^{\prime}$ needles in both cases, thus the strategy applied doesn't change the microstructure of the Ti-64 alloy. The $\beta$ phase is impossible to observe directly by EBSD therefore $\beta$ phase reconstructions from Fig.2 (a) and (b) EBSD images were carried out using the ARPGE software [9]. The Fig. 2 (c) and (d) show $\beta$ phase microstructure after reconstruction. The black areas are not porosity but areas that have not been reconstructed. In the Fig. 2 (c) corresponding to the CL laser strategy, small square areas of the order of $60 \mu \mathrm{m}( \pm 9 \mu \mathrm{m})$ are observed. The laser scanning direction is rotated by $90^{\circ}$ between each layer (Fig. 1) which generated periodic melt pools in each layer that lead to a grid microstructure of $\beta$ phase with different crystallographic orientations. These results have been seen in the literature [10]. In the Fig. 2 (d), the LB strategy develops larger $\beta$ grains, with a variation of size from 20 to $200 \mu \mathrm{m}$, because LB strategy induces a larger melting area than CL strategy. The average size of $\beta$ grains is $110 \mu \mathrm{m}( \pm 43 \mu \mathrm{m})$.
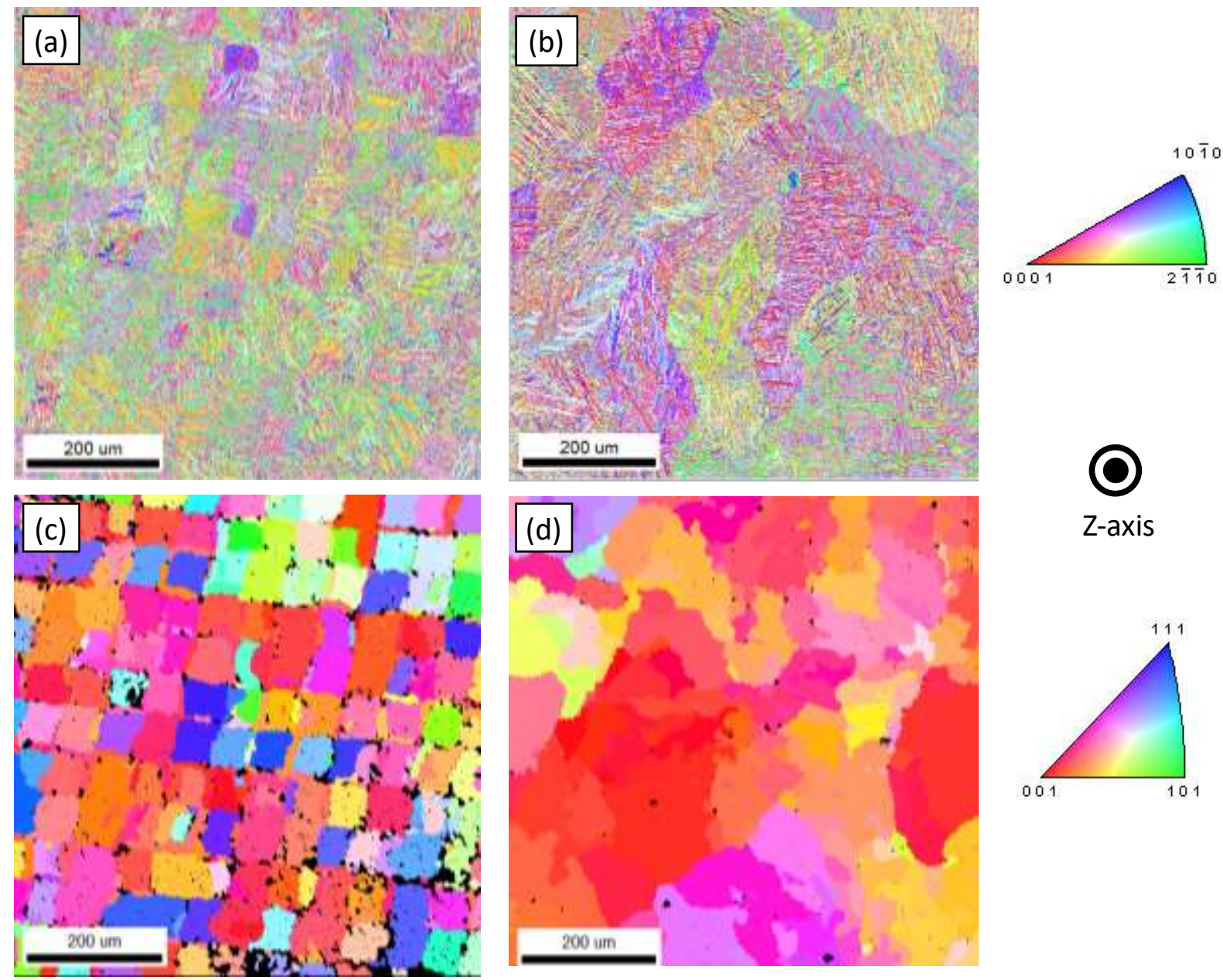

Fig. 2: EBSD orientation maps in the plane perpendicular to the building direction, [001] showing the microstructure of Ti-64 after the stress-relieve treatment. $\alpha^{\prime}$ microstructures with the $C L(a)$ and $L B(b)$ strategies. Reconstructed $\beta$ phase with the $C L(c)$ and $L B(d)$ strategies

The EBSD maps of the stress-relieved sample Fig. 3 (a) shows the needle microstructure of the $\alpha^{\prime}$ martensite with LB. The Fig. 3 (b) shows the EBSD map of the sample after HIP with needles that are thicker than in Fig.3 (a). This is due to the slow HIP treatment cooling that turned the $\alpha^{\prime}$ phase into $\alpha$ thick needles with the $\beta$ phase between the $\alpha$ needles [11]. During HIP treatment at $920^{\circ} \mathrm{C}$, the volume fraction of $\alpha$ is very low and there is coalescence of the needles. During slow cooling, the needles become wider. 

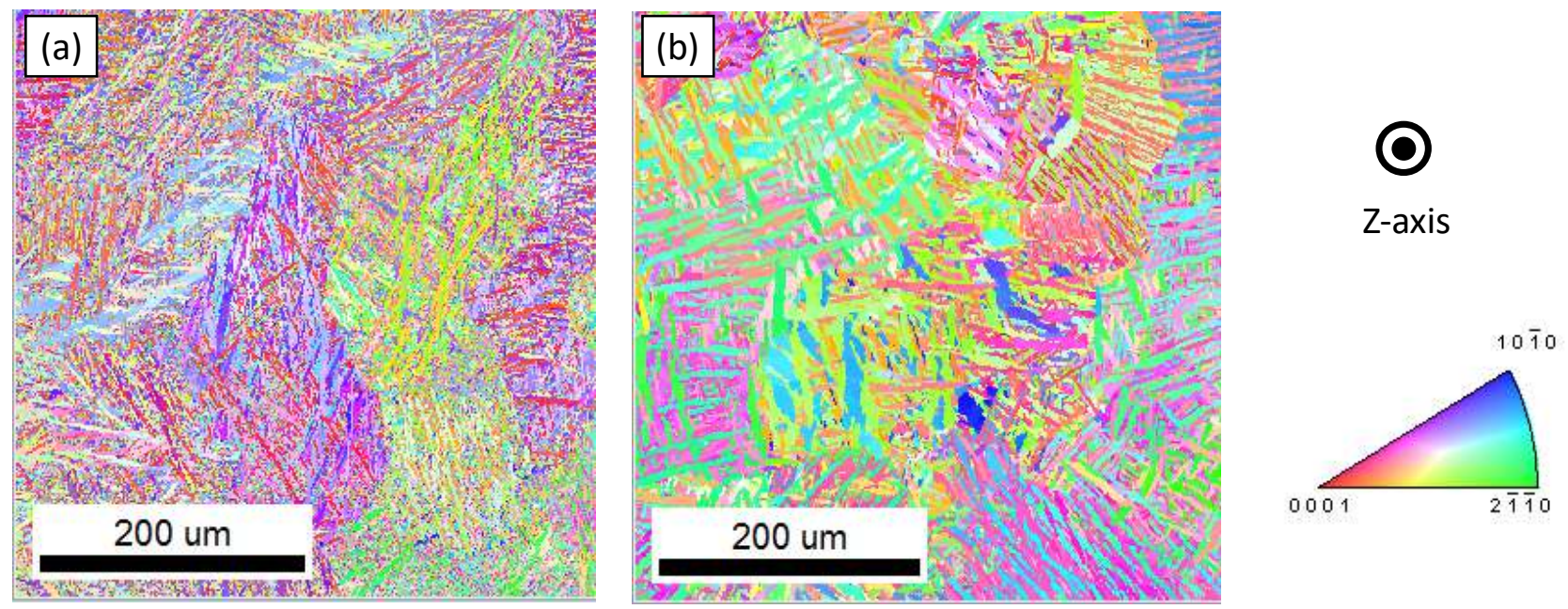

Fig. 3: EBSD orientation maps type IPF [001], showing the microstructure of $\beta$ phase investigated in (a) LB strategy stress-relieved; (b) LB strategy after HIP. The orientation maps are perpendicular to Z-axis.

\subsection{Mechanical properties}

Tensile tests have been carried to study the influence of both strategy on mechanical properties of Ti64 samples. The tensile test results are presented by plotting the evolution of the maximum strength $(\mathrm{Rm})$ as a function of the elongation at failure (A\%) in Fig. 4. The mechanical properties of each condition have been compared: 5 samples of CL, 5 samples of LB strategy with the power $\mathrm{P}_{1}, 5$ samples of LB strategy with the power $\mathrm{P}_{2}, 5$ samples of LB strategy with the power $\mathrm{P}_{1}$ and a HIP post-treatment. The laser power $\mathrm{P}_{2}$ used is higher than the laser power $\mathrm{P}_{1}$.

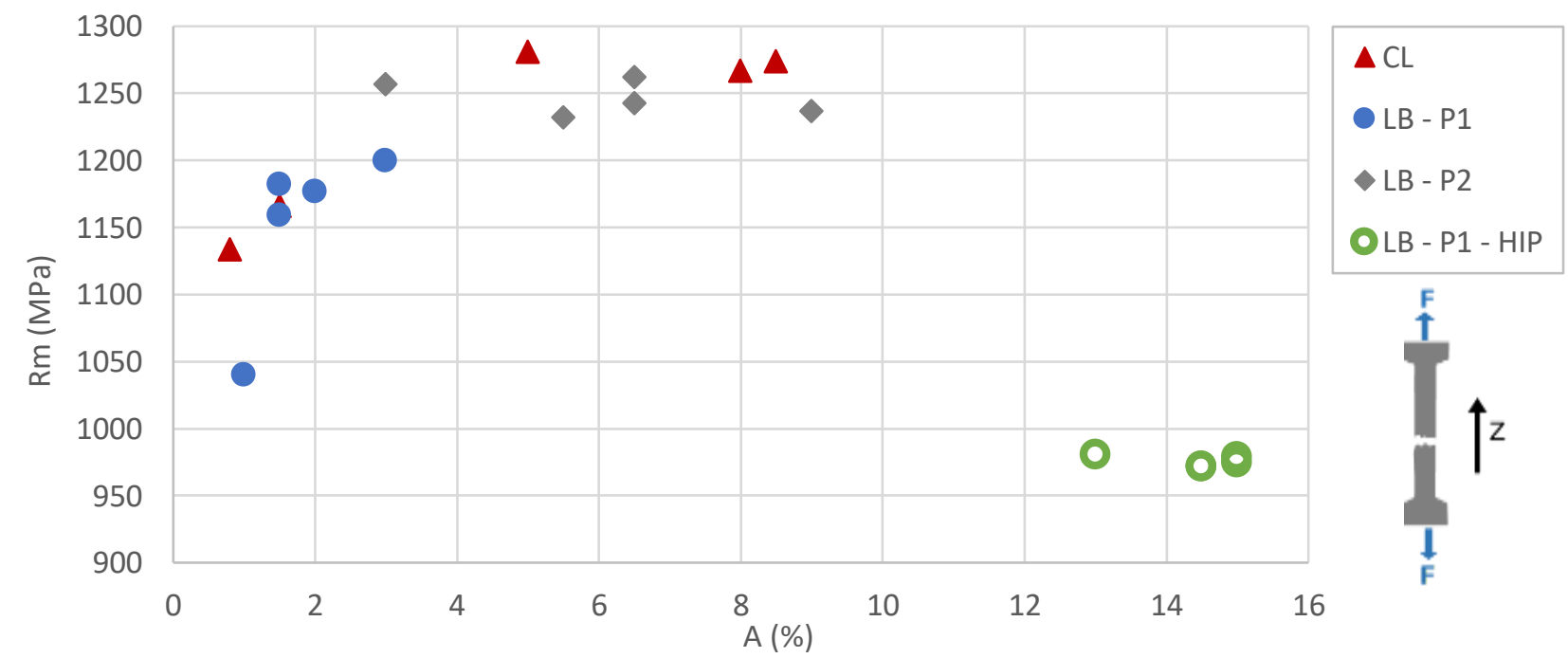

Fig. 4: Maximum strength as a function of the elongation at fracture in tension. Specimens elaborated in $Z$ direction with different conditions

In the case of the stress-relieved samples made by CL and LB-P 1 with respectively a strength around $1150 \mathrm{MPa}$ and $1050 \mathrm{MPa}$ (Fig. 4), the low elongation value at failure combined with a low mechanical strength indicates a premature failure of the specimen after plastic deformation. For the other specimens made by CL, the maximum strength is extended over a range of 1150 to $1200 \mathrm{MPa}$ and the elongation at failure is between 1.5 and $9 \%$. In the case of the LB- $\mathrm{P}_{1}$ strategy the maximum strength is around $1170 \mathrm{MPa}$ and the elongation at failure varies from 1 to $3 \%$. Samples with the CL strategy have the highest dispersion. With the LB strategy, it is possible to improve behavior by increasing power $\left(\mathrm{P}_{2}>\mathrm{P}_{1}\right)$ with a maximum strength average around $1250 \mathrm{MPa}$ and elongation at failure that varies from 3 to $9 \%$. The LB- $\mathrm{P}_{2}$ condition thus allows to obtain characteristics identical to the classic strategy but makes it possible to melt a larger volume of powder with a much higher productivity. 
After HIP treatment, the ductility of the most unfavourable condition (LB-P 1 ) is significantly improved. The elongation increases from $2 \%$ for stress-relieved samples to $15 \%$ for samples after HIP. Conversely, the maximum resistance decreases since it goes from $1170 \mathrm{MPa}$ in average for the stress-relieved sample to $970 \mathrm{MPa}$ after HIP. The fall in mechanical strength is attributed to the transformation of the martensitic structure towards equilibrium phases $(\alpha+\beta)$.
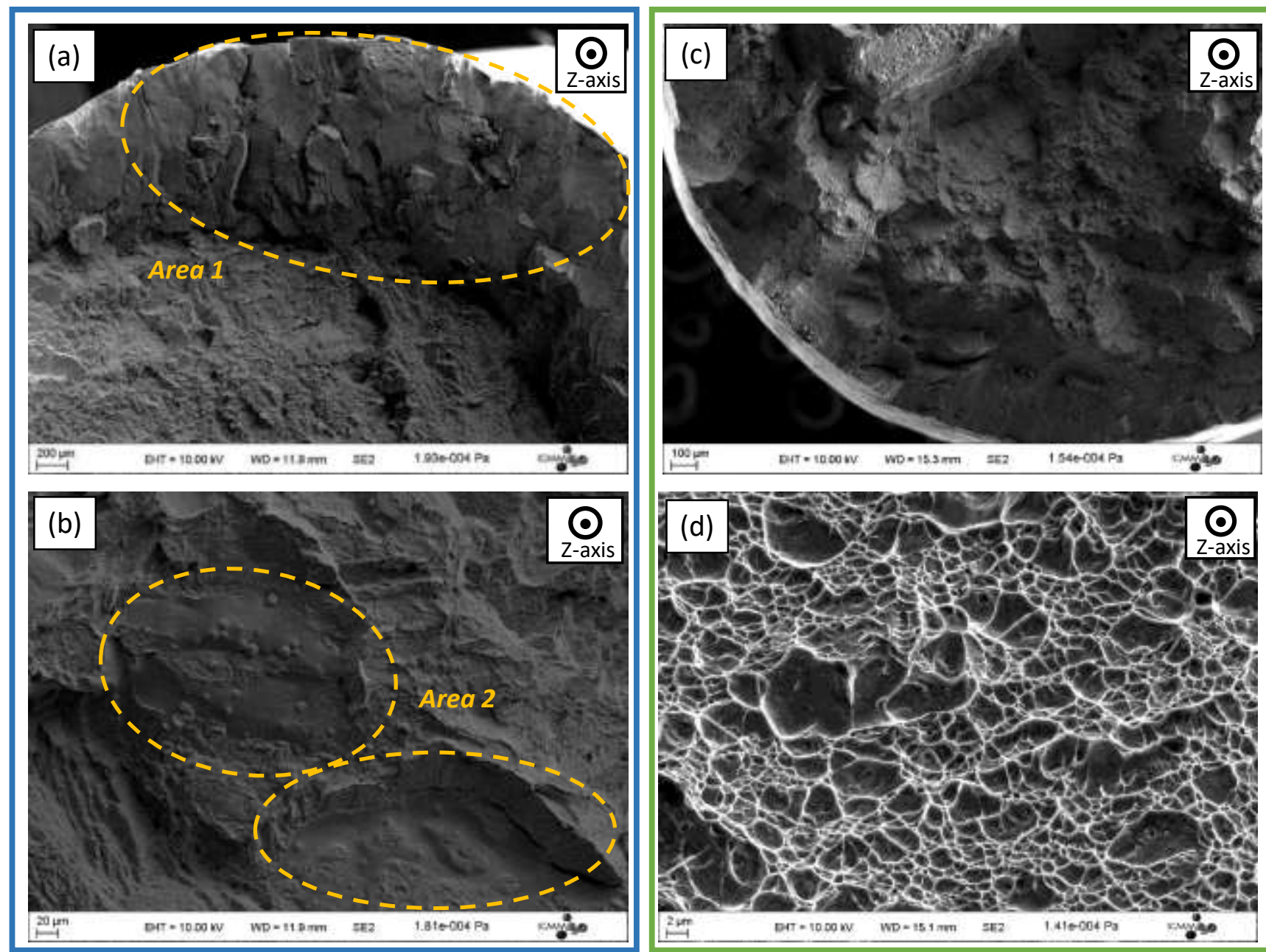

Stress-relieved

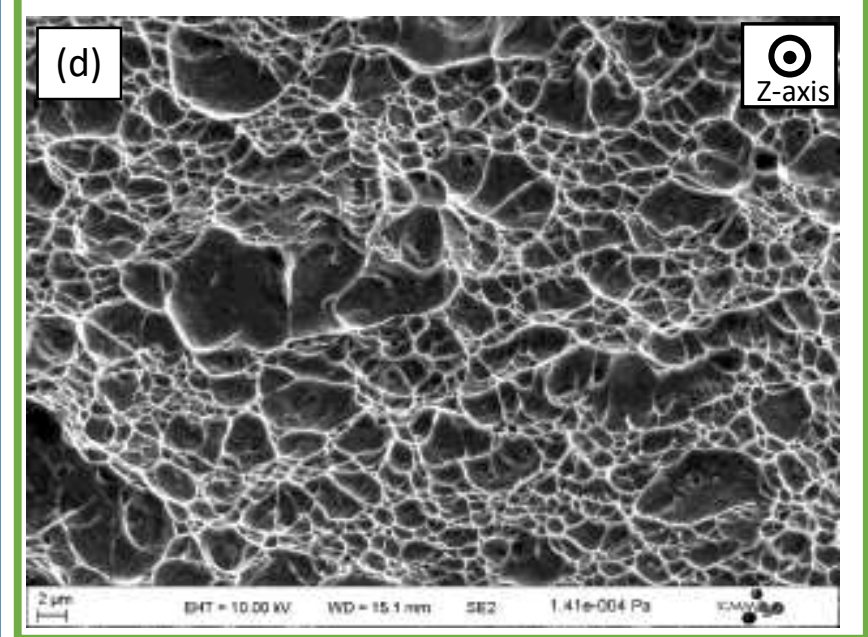

HIP

Fig. 5: SEM observation of fracture surfaces of tensile specimen built in the Z-axis direction with the LB strategy and stress-relieved $(a)$ and (b) or after HIP treatment $(c)$ and $(d)$

Fig. 5 (a) shows two types of area on the stress-free sample with LB. The edge of the specimen (area 1 ) is composed of smooth surfaces and steep steps inclined about $45^{\circ}$ from the tensile direction corresponding to a shear deformation. This stress-relieved specimen has a typical ductile cup-andcone fracture. The zoom Fig. 5 (b), shows flat porosities containing partially melted powder (area 2) in the center of the specimen. Moreover, dimples are visible and indicates a ductile fracture. Specimens after HIP post-treatment, Fig. 5 (c) shows a fracture surface with alternating smooth surfaces, fracture "steps" and dimples. A study at higher magnification (Fig. 5 (d)) highlights the presence of dimples on almost the entire fracture surface which is once again characteristic of a ductile fracture. In addition, there is no visible porosity on the LB fracture surface.

\section{Discussion}

The productivity of the LB strategy is $43.20 \mathrm{~cm}^{3} / \mathrm{h}$ and the productivity of the CL is $12.96 \mathrm{~cm}^{3} / \mathrm{h}$. Thus, productivity of LB strategy is three times higher than CL strategy with a larger melting area, therefore the LB strategy is interesting to have a faster melting process. The EBSD studies have shown that for both strategies, the resulting microstructure is composed of needles of martensitic $\alpha$ '. 
However, the parent $\beta$ grains are different. With the CL strategy, the $\beta$ grain size (about $60 \mu \mathrm{m}$ ) is related to the lasing strategy that leads to a paving structure. With the LB strategy, the $\beta$ grains are bigger with an average of $110 \mu \mathrm{m}$. The strategy changes the size and organisation of the $\beta$ grains but the $\beta$ grains still contain $\alpha^{\prime}$ martensite with both strategies. For the LB with the power $\mathrm{P}_{2}\left(>\mathrm{P}_{1}\right)$, the mechanical properties are similar than for the classic strategy CL. The maximum strength is around $1250 \mathrm{MPa}$ and the elongation at break goes from 3 to $9 \%$ with a strong dispersion. The SEM observation of the fracture surface of the LB samples highlights a ductile failure with dimples. Ductility drop is related to the presence of porosity which are visible on LB SEM fractography. The HIP post-treatment has an influence on the LB sample properties. The EBSD microstructures show that HIP generates a growth of the microstructure with the appearance of the $\alpha$ phase in needles and $\beta$ phase between needles. This post-treatment increases the ductility of the material up to $15 \%$. This can be explained in two ways: either the change of microstructure in $(\alpha+\beta)$ after HIP generates an increase in ductility, or the HIP close the porosities which leads to an improvement of the ductility.

\section{Conclusion}

The microstructure and the mechanical properties of samples elaborated by LB strategy and the CL strategy were compared. The following conclusions were drawn from this work:

- The productivity of the LB strategy is three times higher than that of the CL strategy

- The LB strategy gives similar mechanical properties than the CL strategy.

- The microstructure obtained by CL and LB strategies both give a martensitic needle microstructure but the parent $\beta$ grains are larger with the LB strategy.

- The HIP post-processing induces the formation of $(\alpha+\beta)$ equilibrium phases

- Ductility of the material reaches $15 \%$ with HIP post treatment.

\section{References:}

[1] J. Kruth, L. Froyen, J. Vaerenbergh, P. Mercelis, M. Rombouts and B. Lauwers, "Selective laser melting of iron-based powder," Journals of Materials Processing Technology, vol. 149, pp. 616-622, 2004.

[2] D. Teng, D. Pal, H. Gong, K. Keng, K. Briggs and N. Patil, "A review of defectmodeling in laser material processing," Additive Manufacturing, vol. 14, pp. 137-147, 2017.

[3] J. Choi, G. Shin, S. Yang, D.-Y. Yang and J.-S. Lee, "Densification and microstructural investigation of Inconel 718 parts fabricated by selective laser melting," Powder Technology, vol. 310, pp. 60-66, 2017.

[4] T. DebRoy, H. Wei, J. Zuback, T. Muckherjee, J. Elmer, J. Milewski, A. Beese, A. Wilson-Heid, A. De and W. Zhang, "Additive manufacturing," Progress in Materials Science, vol. 92, pp. 112-224, 2018.

[5] L. Thijs, F. Verhaeghe, T. Craeghs, J. Van Humbeeck and J.-P. Kruth, "A study of the microstructural evolution uring selective laser melting of Ti-6Al-4V," Acta Materialia, vol. 158, pp. 3303-3312, 2010.

[6] D. Banerjee and J. Williams, "Perspectives on Titanium Science and Technology," Acta Materialia, vol. 61, pp. 844-879, 2013.

[7] C. Cai, B. Song, P. Xue, Q. Wei, J.-m. Wu and Y. Shi, "Effect of hot isostatic pressing procedure on performance of Ti6Al4V: Surface qualities, microstructure and mechanical properties," Journal of Alloys and Compounds, vol. 686, pp. 55-63, 2016.

[8] Y. Combres, "Traitements thermiques des alliages de titane," Techniques de l'ingénieur, vol. 3, no. 1335, 2013.

[9] C. Cayron, "ARPGE: a computer program to autolatically reconstruct the parent grains from electron backscatter diffraction data," Journal of Applied Crystallography, vol. 40, p. 1183-1188, 2007.

[10] J. Yang, Y. Hanchen, J. Yin, M. Gao, Z. Wang and X. Zeng, "Formation and control of martensite in Ti6Al-4V alloy produced by selective laser melting," Materials \& Design, vol. 108, pp. 308-318, 2016.

[11] C. Qiu, N. Adkins and M. Attallah, "Qiu_2013_Microstructure and tensile properties of selectively lasermelted and of HIPed laser-melted Ti-6Al-4V," Materials Science \& Engineering, vol. A, no. 578, pp. 230-239, 2013. 